\title{
Development of spiritual and moral personality of student-athletes, based on the educational role of classic works
}

\author{
Venera Volchkova ", Sufiya Karimova, Valeriya Teganyuk, Tanzilya Sagitdinova, and \\ Albina Shamsutdinova \\ Volga Region State Academy of Physical Culture, Sports and Tourism, 420010, Kazan, Russia
}

\begin{abstract}
The article describes and presents the implementation results of a pilot model aimed at the spiritual and moral development of studentathletes' personality using a classic work. The necessity of spiritual and moral development of student-athletes, which is a key component in the formation of a successful athlete, is substantiated in the article. The proposed model contributes to the increase of the spiritual and moral maturity level in the framework of the sports university curriculum. The unified structure of the "Foreign language" discipline is provided. Considering the prior to and after implementation results, the criteria of the spiritual and moral development of athletes when working on the classics in a foreign language class are updated.
\end{abstract}

\section{Introduction}

Taking into account modern reality, when younger generations are more interested in social networks and blogging than in reading books, in consumption than in creation, in personal interests than in public ones, the question arises of what kind of athlete society will encounter in the future. Therefore, it is very important to provide the individual with opportune support using time-proven methods. In our opinion, this can be provided by a higher educational institution with its fundamental approach not only to the educational process in general but also to the upbringing of students in particular. The study involved the first-year student-athletes of Volga Region State Academy of Physical Culture, Sports and Tourism, Russia.

The problem of an athlete's personality formation and his/her effectiveness are relevant and have become the research subject of many scientists. For example, Gogunov E.N. and Martyanov B.I. in their classification of the aspects of an athlete's personality formation identify the Self-awareness group. It includes moral feelings, ethical feelings, self-knowledge, self-observation, self-control, and self-esteem [1]. Particular attention is paid to the personality of student-athletes with disabilities and their inclusion in sports. The work of Kazan researchers is dedicated to this aspect. [2]. If to refer to the athlete's personality map developed by KK Platonov, then $70 \%$ of the points are also devoted to the athlete's personality qualities [3].

* Corresponding author: vi-volchkova@ rambler.ru 
Thus, the versatility and multi-stage formation of an effective athlete is obvious. However, this potential can only remain an opportunity, if it is not realized through appropriately directed upbringing and educational activities, that is, the formation of moral norms of behaviour, ethical norms and aesthetic skills. In his study of students' attitudes toward GTO (physical training standard) N. N. Beznosko highlights the important role of educational activities [4]. Even the health problem of the younger generation, A.A Rayzikh. associates "not so much with socio-economic problems, fragile environment, excessive academic load, but with the weakening of upbringing activities in educational institutions" [5]. In particular, this factor determined the purpose of our article, the description of the model of the spiritual and moral development formation of student-athletes by means of implementing the assignments on a classic work into Foreign Language practical classes, as well as experimental proof of its effectiveness.

\section{MODEL OF FORMATION OF SPIRITUAL AND MORAL DEVELOPMENT OF STUDENT-ATHLETES}

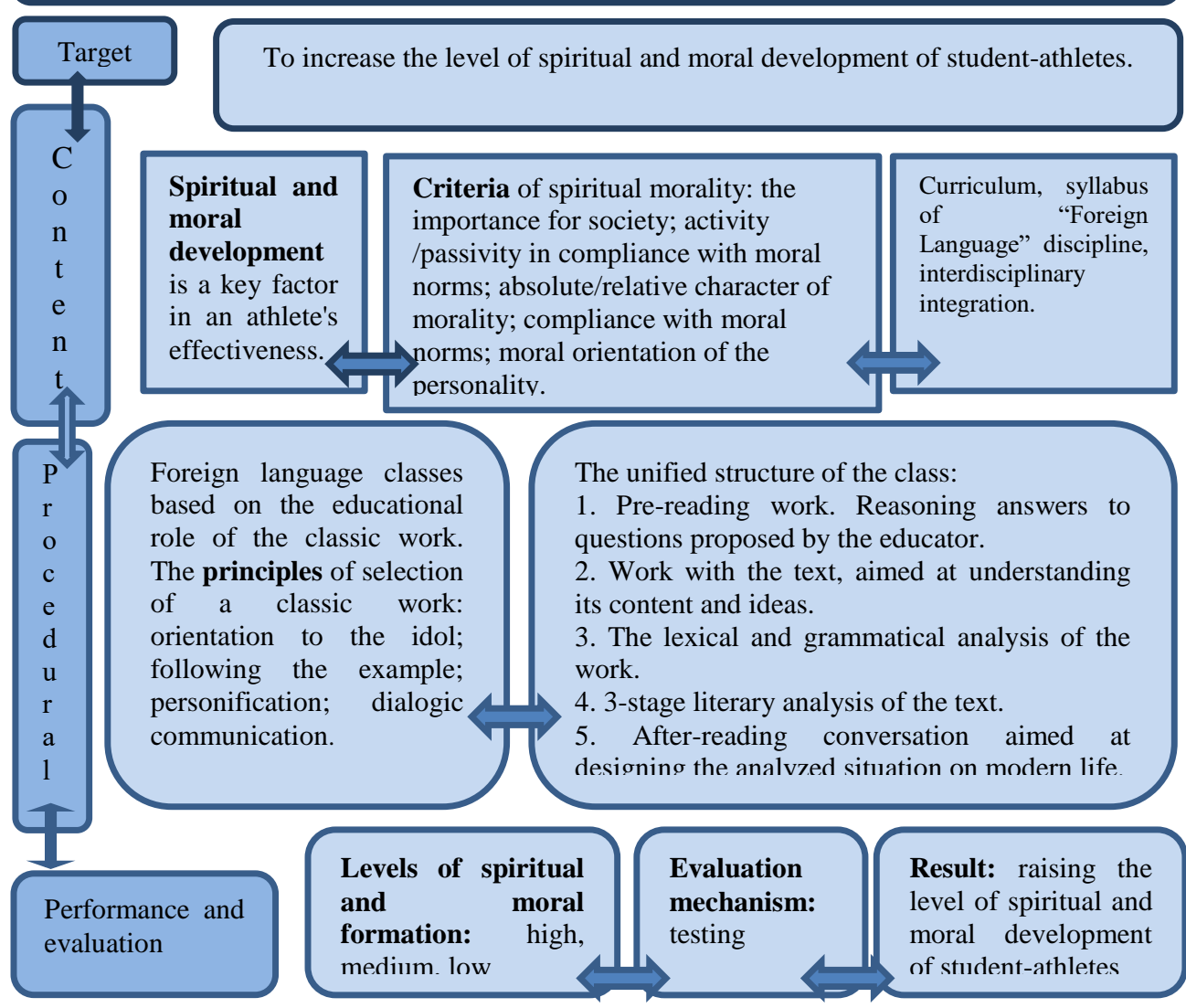

Fig.1. Model of formation of spiritual and moral development of student-athletes.

In modern scientific literature, the issue of the need for the spiritual and moral development of a student is sufficiently studied. The whole point of nurturing a student's personality is to allow it to reveal its creative abilities, that is, to remove restrictions from its creative power [6]. K. Tirri, E. Campbell et al. emphasize the special role of moral upbringing in raising the level of education using the example of schools in Finland, the Netherlands and Iran [7]. In the research of Hing Keung Ma the Chinese theory of adolescents moral education is proposed as an effective concept in working with youth 
$[8,9]$. H. Leenders et al. study the problems of moral development and civic education and experimentally prove the important role of the educator in the formation of these values [9]. The educator at a sports university faces a particularly difficult task, sometimes dealing with an already-formed personality, a full-fledged athlete since it is more difficult to correct already formed life principles than to instill them. Studying the issue of the educational process and sports training integration Zotova F.R. et al. emphasize the important role of a teacher-trainer [10].

Fig. 1 shows the pilot model aiming at increasing the level of spiritual and moral maturity of student-athletes. The target block focuses on creating conditions for increasing the level of spiritual and moral formation among athletes by introducing assignments on a classic work into practical classes in a foreign language. The content block reflects the criteria of a spiritual and moral personality, the level of spiritual and moral values formation among student-athletes, as well as the conditions for their formation. The procedural block represents the structure of foreign language classes, which includes reading excerpts from classic works in English, as well as the principles of selecting classic works. The performance-evaluation block reveals the evaluation mechanism and performance indicators for the implementation of the pilot model.

\section{Materials and Methods}

Theoretical and empirical research methods were applied to answer the question. Theoretical methods are the analysis of literature on pedagogy, psychology, teaching methods, and sports activities. Empirical methods are the analysis of the curriculum and syllabus, quantitative and qualitative methods, and pedagogical experiments. The experimental base of the research is the Sports Faculty of Volga Region State Academy of Physical Culture, Sports and Tourism, Russia.

\section{Results and Discussion}

\subsection{The level of spiritual and moral development of student-athletes before the implementation of a pilot model}

The primary task of the study is to determine the level of spiritual and moral values formation among student-athletes. For this purpose, the test "Diagnostics of spiritual and moral values formation among students of a sports university" was used, basing on the method of "Personality moral self-determination" by A. B. Kupreichenko and A. E. Vorobyeva [11]. 188 first-year student-athletes were tested from Majors 49.03.01 Physical Education, educational program specialization - sports training in acyclic sports, sports training in cyclic sports and training in game sports. The results are presented in Table 1.

Table 1. "Diagnostics of spiritual and moral values formation among students of a sports university" test results before the model implementation
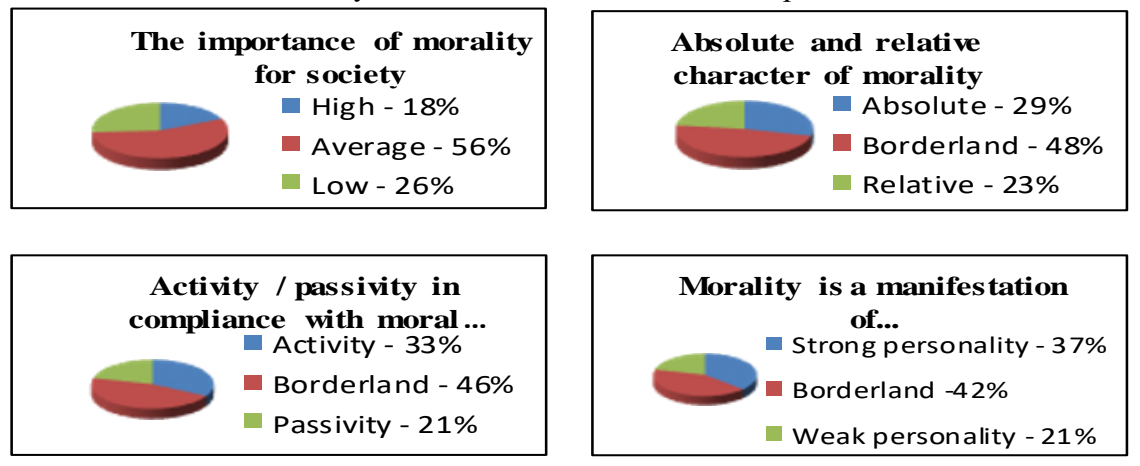

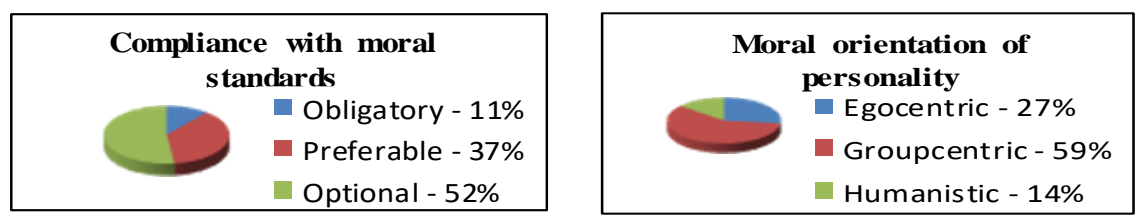

The summarized results indicate that among the first-year student-athletes on September $10,2019,25.8 \%$ have high, $48 \%$ have medium and $26.2 \%$ have low levels of spiritual and moral values.

\subsection{Interdisciplinary integration and the role of the discipline "Foreign language" in the spiritual and moral growth of student-athletes}

The results of the study of the low level of formation of spiritual and moral values in student-athletes confirm the relevance of our research and, in this regard, the issue of interdisciplinary integration comes to the fore. Moreover, Galimov A.M. notes the integration of formal and informal teaching methods, the main goal of which is "to instil in students the habit of continuous learning" and emphasizes "the flexibility of educational programs" [12]. If one turns to the Curriculum for the undergraduate program for Major 49.03.01 Physical Education, with specialization of sports training in acyclic sports, cyclic sports training and training in game sports, then one finds out that $15 \%$ of subjects are noncore, including a number of humanitarian disciplines. It is known that the responsibility for spiritual and moral development from time immemorial was assigned to humanitarian disciplines, presented by a non-core base in the considered curriculum. However, this plan eliminates the confirmed over the years effective element "classic work", which contributes to the spiritual and moral development of students. Taking into account the aforementioned reality, the assignments on classic works were implemented into the "Foreign Language" discipline.

\subsection{A pilot model based on the educational role of the classic work}

The authors made an attempt to design a model of Foreign Language practical classes. It includes reading excerpts from classic works in English with their subsequent lexical and semantic analysis. The developed experimental model course is designed for 104 hours of practical classes. The pilot model includes 15-20 minutes long practical assignments on classic works in a foreign language and is implemented into the syllabus without violating and hindering the system of professional competencies. The choice of classic texts is associated with the fact that literature teaches the reader to sympathize with characters, to resist evil; it forms the worldview through an artistic image [13]. The following principles are to be followed when selecting classic works: the principle of orientation toward an idol, the principle of following the moral example, the principle of personification, and the principle of dialogic communication [14].

The following fragment is an illustration of spiritual and moral education implementation in Foreign Language practical classes with student-athletes who worked on the story "Chameleon" by A. Chekhov. The purpose of the fragment is to form a student's understanding of the absolute nature of morality. It should not change under the influence of external factors. The procedure begins with the pre-reading stage, when an anticipation moment is created. The educator prepares student-athletes for the perception and subsequent discussion of the classic work. This is a so-called warming-up activity, when the students answer thought-provoking questions. Only after the preceding discussion, the 
work (reading and translation) on the classic text begins. At the next stage, students answer the text comprehension questions about the plot, the setting and the main characters. Afterwards the educator proceeds to the grammatical and lexical analysis of the work. In the given case the student-athletes are given the following tasks: to determine the grammatical tenses used in the work and to explain why they are used; to find an example of using Past Continuous and explain why this time is used; to put phrases that describe the dog into two groups with positive and negative connotations. The profound vocabulary work makes possible the final stage of the text literary analysis. Following one of the three types of traditional text analysis (holistic, "image-based", and "problem-based" analysis) [15]. The students discuss the extra linguistic context of the classic work: its title, the image of the author, the author's intention and the message of the text. At the final after-reading stage, the students are asked to transfer the situation from the story for modern life. The conversation includes answers to the following questions: Have you met people like Ochumelov in your sports career? What is your attitude toward such people?

\subsection{Results}

In order to identify the dynamics of spiritual and moral development, we again turned to the methodology of A. B. Kupreychenko and A. E. Vorobyeva. Table 2 shows the test results of first-year students held on May 28, 2020. Control testing results indicate that educators were able to influence the spiritual and moral guidelines of student-athletes and change them for the better.

Table 2. "Diagnostics of the spiritual and moral values formation in students of a sports university" test results after the model implementation
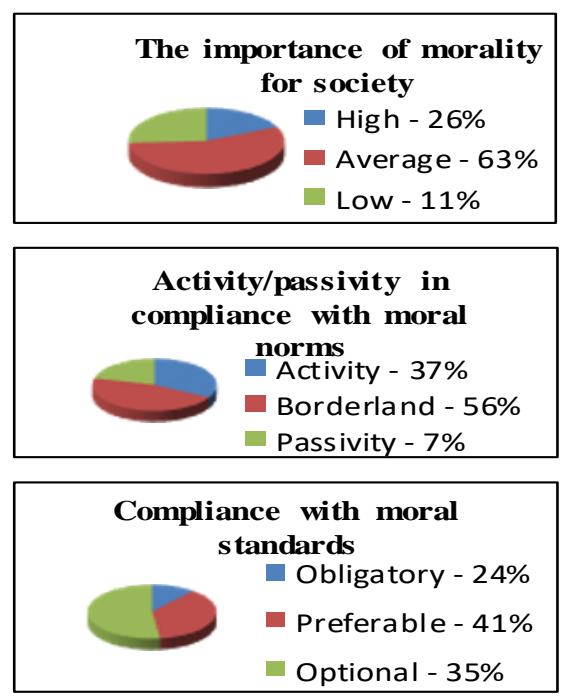
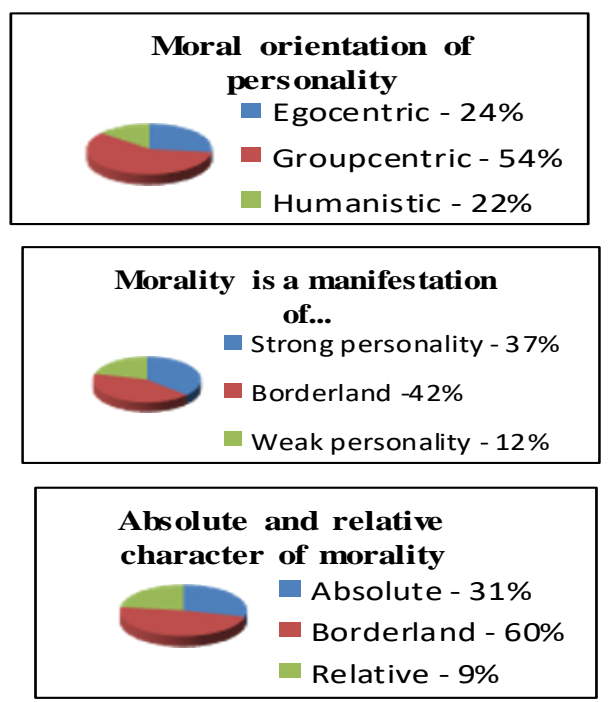

The summarized results of the control test lead to the conclusion that among first-year students on May 28, 2020, 29.5\% of student-athletes have high, 52.6\% - medium and $17.9 \%$ - low levels of spiritual and moral values formation. Thus, the number of athletes with a high level of spiritual and moral values formation increased by $3.7 \%$, students with an average level by $4.6 \%$, and the number of student-athletes with a low level of formation decreased by $8.3 \%$. 


\section{Conclusions}

In the period from September 10, 2019 to May 28, 2020, the pilot model was tested, aimed at the student-athletes' personality spiritual and moral development by means of the classic works. The criteria of spiritual and moral development of a personality were determined. The level of spiritual and moral values formation of students-athletes prior the model implementation, as well as the conditions for their formation, were identified. The model was introduced in the framework of the "Foreign language" discipline. A unified structure of foreign language classes consisting of five stages was developed. The fragment of the practical class is presented. It includes reading and practical assignments on excerpts from the classic works in English. In addition, the principles of classic works selection were determined; the control testing was carried out. It was revealed that the implemented teaching model based on the educational role of classic works, can significantly increase the level of spiritual morality of an athlete.

\section{References}

1. E.N. Gogunov, B.I. Martyanov, Psychology of physical education and sport, URL: https://litresp.ru/chitat/ru/Г/gogunov-evgenij-nikolaevich/psihologiya-fizicheskogovospitaniya-i-sporta/9

2. I.E. Konovalov, R.K. Bikmukhametov, V.I. Volchkova, Y.V. Boltikov, G.R. Danilova, Theory and practice of physical education, 6, 62-64

3. A.S. Kuznetsov, Z.M. Kuznetsova, Russian Journal of Physical Education and Sport, 14(4), 5-7 (2019)

4. N. N. Beznosko, Science and sport: modern tendencies, 4 (21), 85-90 (2018)

5. A.A. Rayzikh, Science and sport: modern tendencies, 4(21), 102-109 (2018)

6. S.N. Sukhanova, Students' spiritual development as pedagogical problem, Stavropol State University's Vestnik, 53, 78-79 (2007)

7. K. Tirri, E. Campbell, L. Gearon, T.J. Lovat, The moral core of teaching (2012)

8. H.K. Ma, Moral competence as a positive youth development construct: a conceptual review (2012)

9. H. Leenders, W. Veugelers, E de Kat, Moral development and citizenship education in vocational schools (2012)

10. F.R. Zotova, V.M. Gaznanova, Sport and academic career of a student-athlete: coach's view (Volga Region Academy of Physical Culture, Sport and Tourism, Kazan, 1(18), 83-89, 2018)

11. L.A. Zakirzyanova, The technique of diagnostics of the moral sphere of the personality (29-35, 2013).

12. A.M. Galimov, Science and sport: modern tendencies, 3 (7), 66-73 (2019)

13. V.Yu.Isak, Literature as a source for spiritual and moral education, URL: https://cyberleninka.ru/article/n/hudozhestvennaya-literatura-kak-istochnik-duhovnonravstvennogo-vospitaniya

14. E.S. Savinov, Sample core educational program of an educational institution. Elementary School (Prosveshcheniye, 2010)

15.E.L. Voitolovskaya, Ways and methods of literary works analysis, URL: https://lit.wikireading.ru/48046 